\title{
¿Es realmente la pluma más poderosa que la espada? Instrumentos de escritura como arma en la historia y la literatura
}

\author{
Julián Monge-Nájera \\ Laboratorio de Ecología Urbana, Vicerrectoría de Investigación, UNED, 2050 San José, \\ Costa Rica; jmonge@uned.ac.cr, julianmonge@gmail.com
}

Resumen: Desde que, según el Talmud Babilónico, estudiantes judios trataron infructuosamente de defenderse de las espadas del ejército romano con sus estiletes de escribir, hasta la actualidad, los instrumentos de escritura han sido usados como arma en la vida real, la literatura, el cine y la televisión, aunque hasta ahora no se había recopilado su historia. En literatura, el primer uso homicida es la pluma fuente como depósito de veneno, en "El Misterio de la Pluma Fuente", de Dorothy Sayers (1893-1957) y el más reciente, "Matando a Cupido", de Laura Levine (2014). En el cine, el primer registro es "The Naked Gun"(1988), con pluma fuente, y el más reciente, "John Wick: Chapter 2" (2017), con lápiz. En televisión, el registro va de "CSI: Miami” (2010) a "Forever" (2015), ambas por pluma fuente en la carótida. En la vida real hay casos que van desde armas militares hasta asesinatos oportunistas. En la Segunda Guerra Mundial, el gobierno británico desarrolló plumas con dagas y plumas explosivas, y las plumas pistola han sido usadas por gobiernos y por delincuentes en Vietnam, Rusia y Corea del Norte. Los casos recientes incluyen a Jason Webster, el "asesino del bolígrafo" de la Universidad de Hull, y al enigmático Señor Xu, el aeropirata chino de la pluma fuente. Sin embargo, en la vida real, el personaje más famoso en darles este uso fue Julio César en el año 44 AC.

Palabras clave: historia de los instrumentos de escritura, historia social, pluma fuente, estilográfica, lápiz.

Abstract: From the time when, according to the Babylonian Talmud, Jewish students tried unsuccessfully to defend themselves from the swords of the Roman army with their writing styli, until the present, writing instruments have been used as weapons in real life, literature, cinema and television, but until now this history had not been compiled. In cinema, the first record is "The Naked Gun" (1988), with fountain pen, and the most recent, "John Wick: Chapter 2" (2017), with pencil. On television, the record goes from "CSI: Miami" (2010) to "Forever" (2015), both by pen wounds to the carotid. In real life, uses range from military weapons to opportunistic assassinations. In World War II, the British government developed pens with daggers and explosive pens; and gun pens have been used by governments and by criminals in Vietnam, Russia and North Korea. Recent cases include Jason Webster, the "pen killer" of the University of Hull, and the enigmatic $\mathrm{Mr}$. $\mathrm{Xu}$, the Chinese fountain pen air-pirate. However, in real life, the most famous person to give them this use was Julius Caesar in 44 BC.

Key words: history of writing instruments, social history, fountain pen, ball-pen, pencil. 
La idea, reflejada en la frase inglesa "la pluma es más poderosa que la espada", lleva más de dos milenios en los registros históricos. Por ejemplo, en la Epístola a los Hebreos, 4,12, se lee: "La palabra de Dios es viva y eficaz, más penetrante que espada de doble filo". Pero al ir a la interpretación literal, el resultado puede ser muy diferente, como cuando, hace dos milenios, estudiantes del talmud trataron de defenderse de las espadas del ejército romano con sus estiletes, demostrando de manera trágica que la espada es más poderosa que, al menos, el estilete de escribir (Talmud Babilónico, https://bit.ly/2U1uF11).

Mi esposa me contó que, cuando era adolescente, sus compañeros usaban sus Lami Safari como dardos, una práctica escandalosa para el "estilófilo", pero natural si se combina la mente adolescente con el innegable parecido de las puntas de pluma con las puntas de flecha. En este artículo repasaré el tema de los instrumentos de escritura como arma, que hasta donde pude investigar nunca antes ha sido tratado en un artículo formal, aprovechando que Internet permite una búsqueda detallada de cualquier mención al tema dentro de billones de textos, tarea imposible hace solamente unas décadas.

Dado que escribo para CoRis, quiero iniciar con los instrumentos de los filósofos. Hace un par de décadas el filósofo australiano Graham Pont, de visita en Costa Rica, encontró en el mercado central de San José algo inesperado: lo que los italianos llaman passito, o sea, un vino que no es hecho de uvas frescas, sino de pasas, y que por lo concentrado de su sabor era particularmente valorado en la antigüedad (según Lucius Junius Moderatus en su libro De Agricultura 12.39.1). "Imagínese Julián — me dijo — ¡lo más probable es que este fuera el tipo de vino que bebieron Sócrates, Platón y Aristóteles!", y sirvió dos copas.

Nunca se me había ocurrido colocarme mentalmente en la mesa de algún gran filósofo griego y tratar de percibir el mundo como él; saboreando el mismo vino, escuchando el mismo ruido del tráfico urbano de la época, es decir, cascos de caballo; lavándome con jofaina; y escribiendo con lo que fuera que escribían en aquella época. "Con plumas de ave" — supuse inicialmente - pero resulta que ni Sócrates, ni los presocráticos, ni sus sucesores de la Grecia antigua, escribieron con pluma.

Los filósofos griegos y romanos tomaban notas rápidas con estiletes metálicos en tabletas recubiertas de cera, que se podían borrar calentándolas (Figura 1 y 2). 


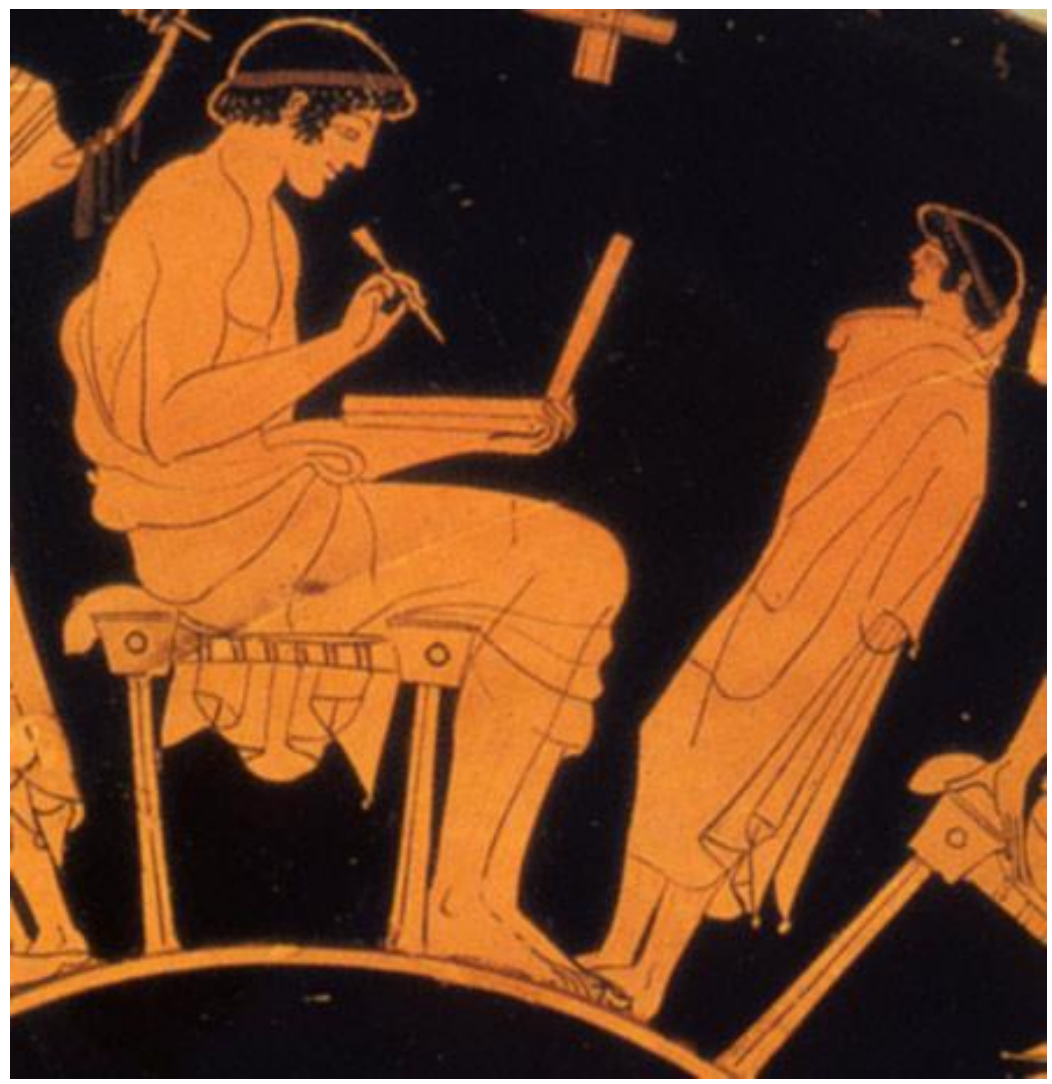

Figura 1. Vasija griega: escribiendo con estilete sobre tablilla de cera, pintura por el artista Douris, sobre cerámica (c. 500 BC), Museo de Berlín. https://goo.gl/HhsmWB

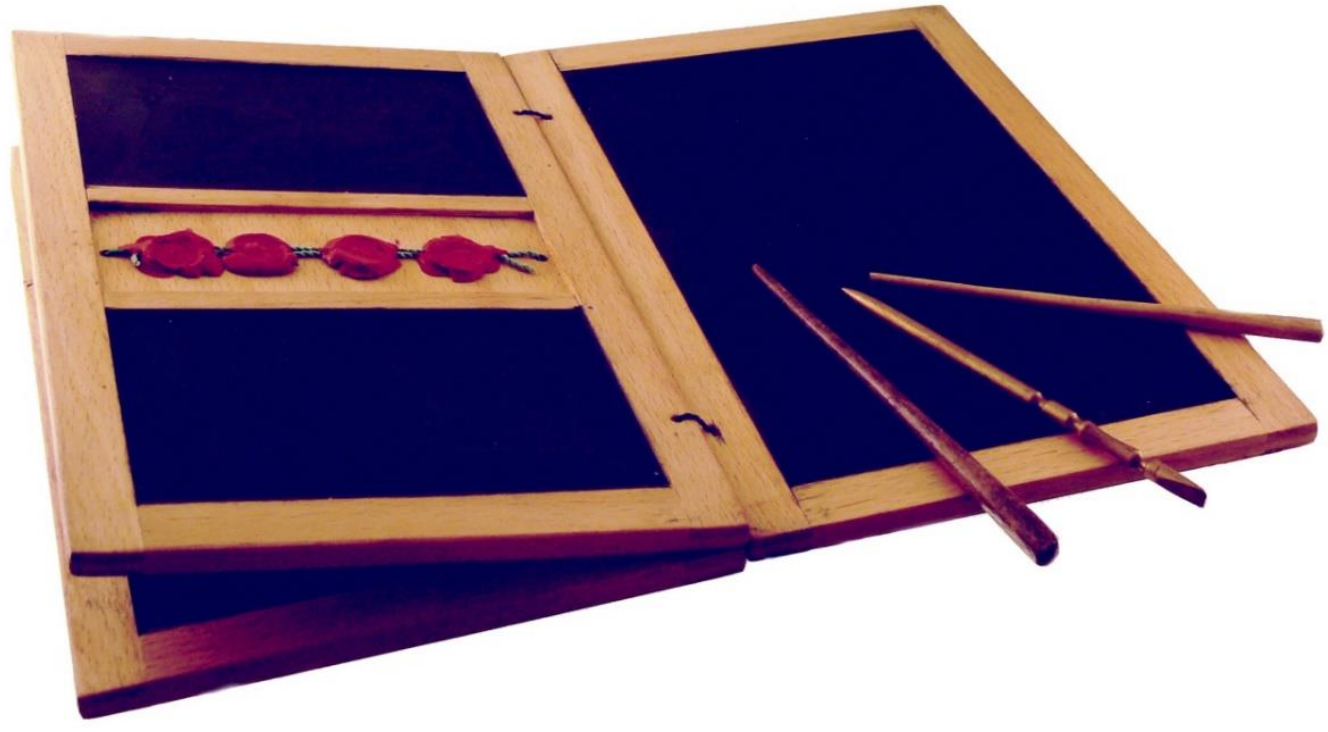

Figura 2. Reconstrucción de tableta romana de cera con tres estiletes. Museo ReissEngelhorn, foto por Andreas Praefcke. https://goo.gl/SdC4YM 
La escritura formal se hacía sobre papiro con caña vegetal o palillero (un palito o hueso con punta metálica) — ambos de origen egipcio (Figura 3).

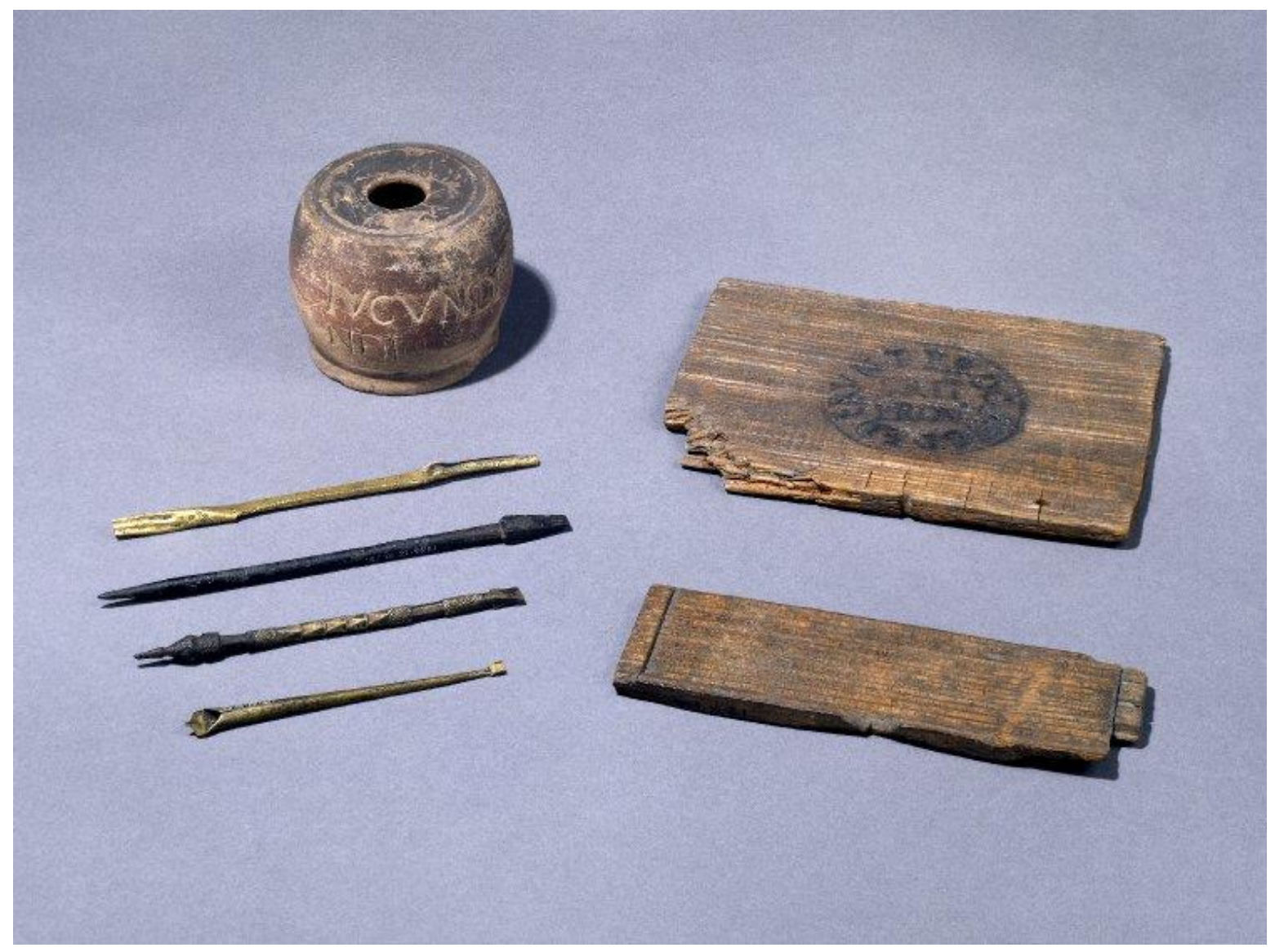

Figura 3. Equipo romano de escritura: incluye palillero y pocillo para la tinta (escritura formal); y tableta encerada y punzones (notas rápidas). https://goo.gl/GNzJdC

En el siglo tercero se comenzó a usar también el pergamino (piel de cabrito o similar). La pluma de ave, omnipresente y barata, no se usaba en aquella época. Isidoro de Sevilla (c. 556-636) fue de los primeros pensadores en cambiar a la por entonces novedosa tecnología de la pluma de ave. Los primeros instrumentos de escritura, susceptibles de usarse como arma, pudieron ser el estilete y el palillero (no incluyo instrumentos menos especializados: los cinceles y martillos con los que se escribió el Código de Hammurabi c. 1754 AC).

Otro cambio tecnológico que afectaría a los instrumentos de escritura, el papel, tomaría tiempo, y Guillermo de Ockham, Alberto Magno, Tomás de Aquino y Roger Bacon pueden haber sido los primeros grandes filósofos occidentales que escribieron sobre papel. De hecho: "Los biógrafos han mantenido que Juan de Fidanza, molesto con los escritos de Bacon, le negó libros, papel e instrumentos de escritura" (Krstović, 1995). En todo caso, probablemente todos ellos ya escribieron sus magnas obras con las novedosas plumas de 
ave, que funcionaban muy bien sobre papel, y que solo habrían de aparecer como arma a fines del siglo 20 .

\section{En la literatura}

Mucho tiempo después se puso a punto la pluma fuente o pluma estilográfica, que lleva en sí misma el depósito de tinta, invento de autoría aun discutida entre los expertos, y que ha existido por siglos en forma primitiva, hasta volverse popular a fines del siglo 19. Con este nuevo instrumento, surge también una forma nueva de matar. En el cuento "El Misterio de la Pluma Fuente", la escritora inglesa Dorothy Sayers (1893-1957, Figura 4) presenta un caso en que el asesino reemplaza la tinta con veneno, para verterlo secretamente en la bebida de su víctima (McGregor \& Lewis, 2000).

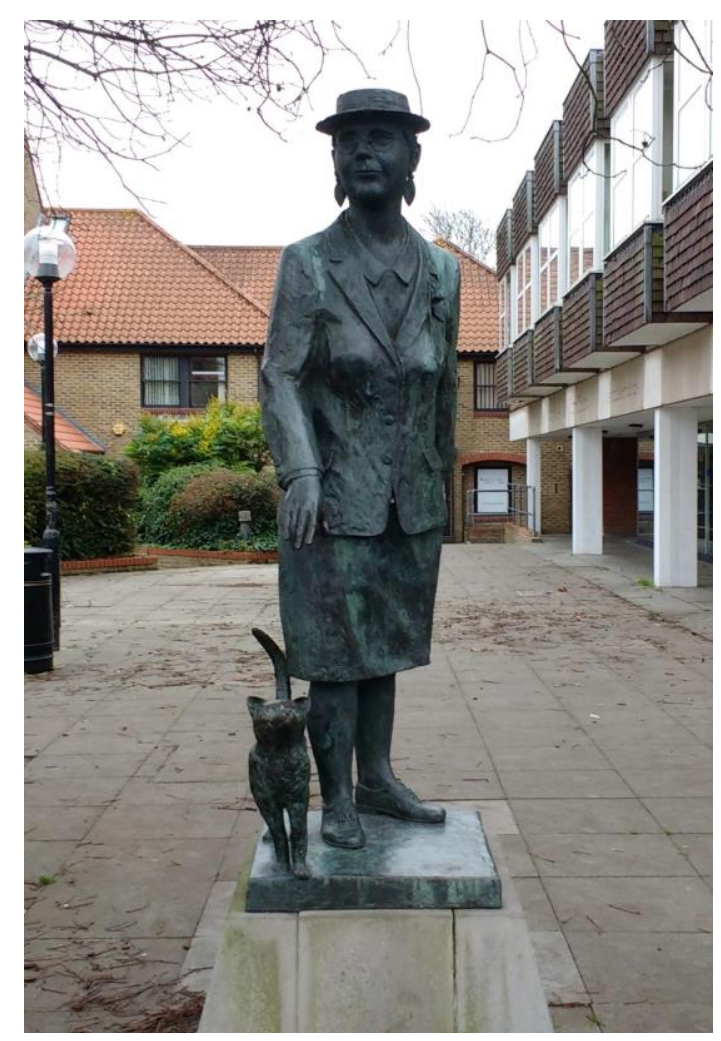

Figura 4. La escritora Dorothy_L._Sayers, primera en hablar del veneno oculto en el depósito de tinta de la pluma fuente; fotografía por General Johnson Jameson. www.wikimedia.org.

En el cuento Fecha límite, Robert J. Daniher nos relata del amor de un escritor por "su confiable pluma fuente", y de cómo ésta le sirve de inspiración para matar con ella y escribir sobre el crimen con conocimiento de primera mano. Un detalle llamativo es que el asesino se ve obligado a lavarla porque, tras haberla usado en una arteria, "escribía con un tinte rojizo" (Daniher, 2007). Otras ideas, aun sin desarrollar plenamente en la literatura, incluyen al asesino que rellena la pluma con sangre para escribirle notas a la policía (al 
estilo de Jack el Destripador), y el vampiro que usa su pluma fuente "para llevar oculto un bocadillo" de sangre para el camino (Fountain Pen Network, 2014b).

En la novela Matando a Cupido, de la serie Jaine Austen Mysteries (Figura 5), la escritora estadounidense Laura Levine nos presenta una caja misteriosa que podía esconder la pistola asesina. Pero, ¡sorpresa! La caja contiene una colección de plumas antiguas, incluyendo una Esterbrook de 1920. Su personaje, Jaine, aliviada, recuerda como el sospechoso Barry le mostró lo que había en la caja:

"Desenroscó la base, mostrando el recipiente de tinta... Me sentí agradecida de que no fuera un arma. Y luego caí en la cuenta: ¡qué fácil habría sido para Barry llenarla con cianuro, y usar la fina punta para inyectarlo en un bombón!. Era una inocente pluma, ¿o tenía frente a mí el arma asesina?" (Levine, 2014).

Seguramente Dorothy Sayers habría estado encantada de ver que su idea regresaba a la vida casi un siglo después.

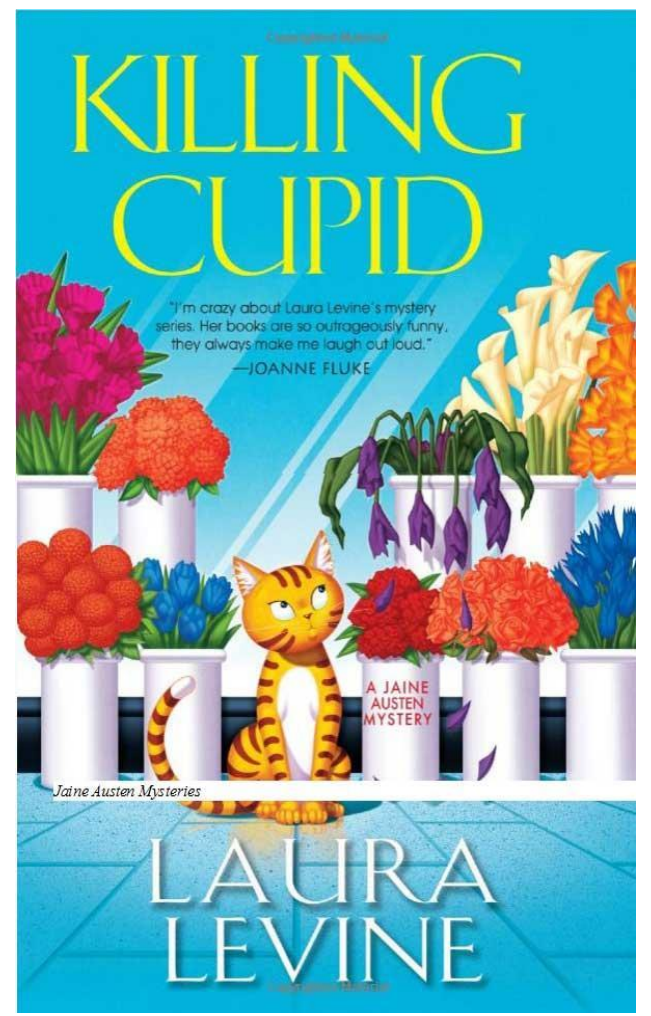

Figura 5. Portada de Killing Cupid, Kensington Books, Nueva York. https://goo.gl/BrY58J

Para concluir la sección sobre literatura, tal vez la siguiente cita resulte particularmente agradable a quienes han hecho de los libros su mundo: 
¿Cuánta diferencia vaya de mojar la péñola de la tinta a teñir la lanza en la sangre, y estar rodeados de libros o estar cargados de armas, de estudiar cómo cada uno ha de vivir o andar a saltear en la guerra para a su prójimo matar!

(Antonio de Guevara, Reloj de príncipes, 1529, citado por Salvo, 1989)

\section{En el cine}

Revisando películas del periodo 1980 a 2017, Lauren O'Callaghan identificó ocho personajes cinematográficos que mueren por pluma, bolígrafo o lápiz (O'Callaghan, 2017).

En la película de 1983 Nunca digas nunca jamás (Figura 6), el Agente 007 recibe del personaje "Q" una pluma fuente Montblanc 149 — decorada con la bandera británica — que dispara micro-bombas. Su víctima es la espía Fatima Blush, quien dejándose llevar por un capricho, antes de matarlo le pide que le firme una declaración de que ella fue su mejor amante (McClory \& Whittingham, 1983; Fandom, 2018).

En The Naked Gun (1988) un "pez luchador japonés" de \$20 000 es atravesado accidentalmente con una invaluable "pluma samurái, regalo del emperador Hirohito". Un año después, en Batman (1989), el Guasón mata a su víctima con una pluma de ave, obviamente muy afilada para escribir, lanzándola desde corta distancia a la garganta, para acabar declarando " ¡verdaderamente la pluma es más poderosa que la espada!”.

De una manera menos directa y obvia, el viejo Señor Jones, interpretado por Sean Connery, vence a un nazi lanzándole tinta a los ojos con su pluma fuente en Indiana Jones and the Last Crusade (1989).

En Casino (1995), un mafioso interpretado por Joe Pesci hiere furiosamente a un cliente irrespetuoso que no supo agradecer cuando le devuelven un "fino bolígrafo" que tenía descuidado sobre el mostrador del bar. Un año después, en From Dusk Till Dawn (1996), el personaje llamado Frost mata a un vampiro atravesando su corazón extracorpóreo con el lápiz de una camarera. La escena recuerda el cuento escandinavo El gigante sin corazón (https://www.uncuentotradicional.com.ar/gigante-sin-corazon). 


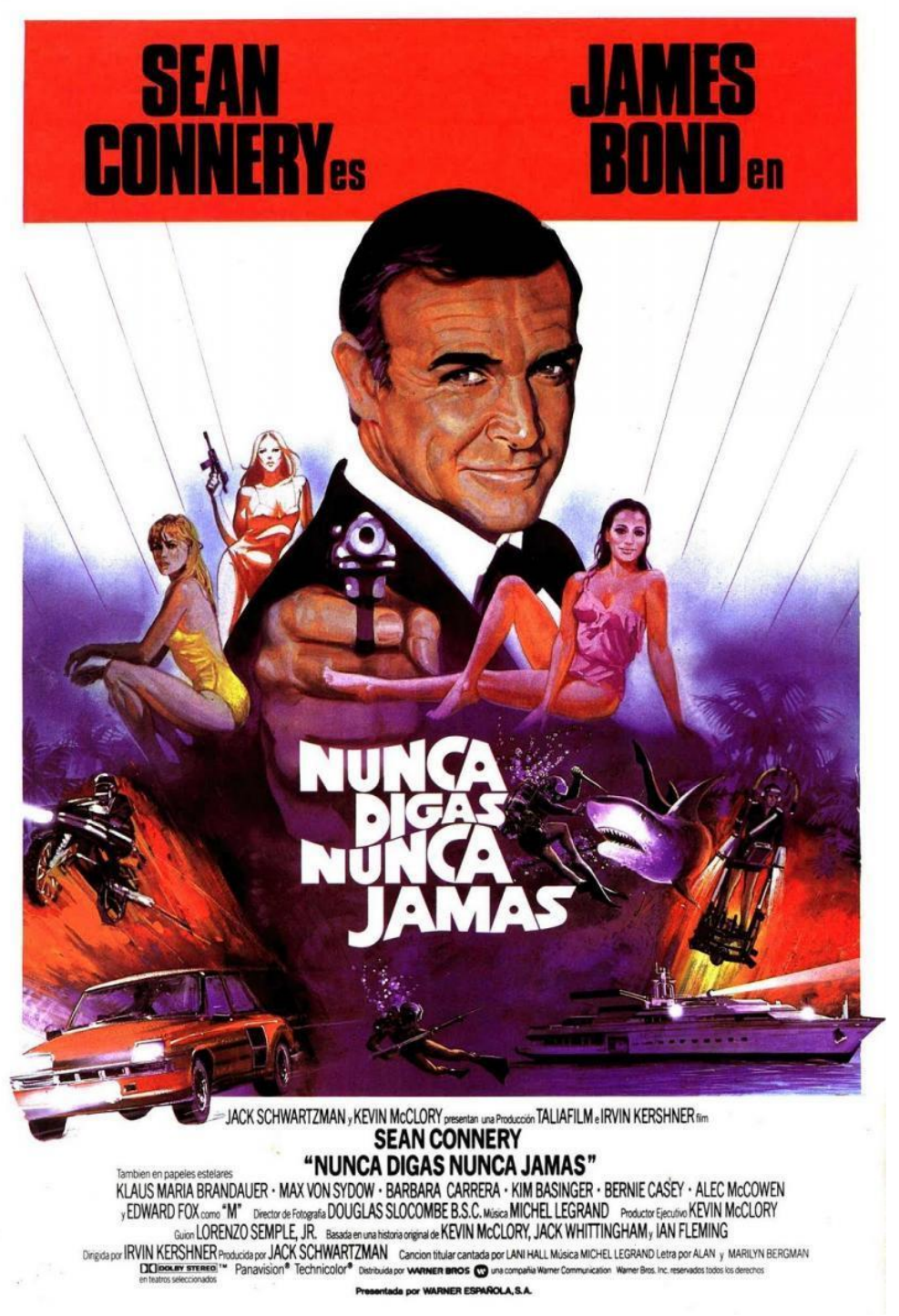

Figura 6. Película Nunca digas nunca jamás (1983). https://goo.gl/A5XGW1

En Grosse Pointe Blank (1997), el asesino profesional Martin Blank mata a un atacante desangrándolo con una pluma o bolígrafo en la garganta. Justo detrás de ambos, un cartel dice "El futuro no está escrito". En The Bourne Identity (2002), el amnésico Jason Bourne se defiende de un atacante clavándole un bolígrafo bic en el dorso de la mano.

Regresando a la garganta, en Red Eye (2005), Rachel McAdams le clava un bolígrafo en la garganta a Cillian Murphy para poder escapar de un avión.

Pero tal vez la escena más famosa es de la película The Dark Knight (2008), en que el Guasón ofrece a su público un truco de magia. Clava un lápiz en la mesa, y cuando uno de los personajes lo ataca, el Guasón lo golpea contra le mesa, haciendo desaparecer el lápiz dentro del ojo de la víctima. Esta escena está basada en hechos reales. Debido a la delgadez de los huesos de la cuenca ocular, es posible insertar un objeto en el cerebro entrando por el ojo, sea por accidente (ha ocurrido con lápices, patillas de anteojo y palillos chinos de 
comer), o como uno de los medios más atípicos de suicidio de los que se tenga registro médico (Lunetta, Ohberg \& Sajantilla, 2002). Sin embargo, con los debidos cuidados médicos, la víctima del Guasón pudo haber sobrevivido con secuelas mínimas (Hill, 2013).

El uso más reciente en el cine parece ser en la película John Wick: Chapter 2 (2017). Es, además, la escena más compleja de todas las que han mostrado un instrumento de escritura como arma, pues acá el sicario John Wick se defiende de varios atacantes clavándoles lápices en garganta, rostro, oído y columna vertebral; para esto último, coloca el lápiz contra la pared, para darle estabilidad, y estrella la nuca de su víctima, penetrando la columna vertebral.

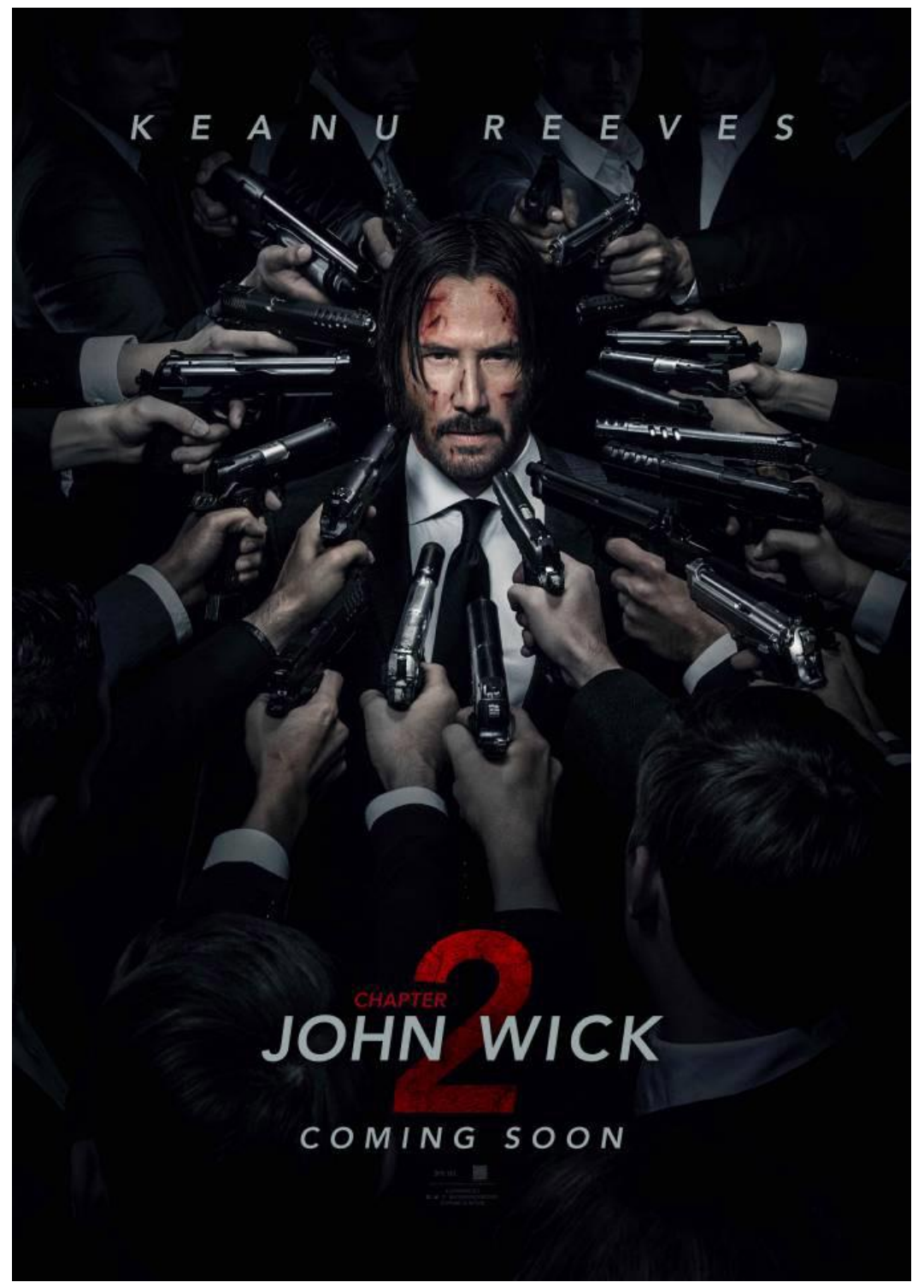

Figura 7. Película John Wick: Chapter 2 (2017). https://goo.gl/Tg6MBY 


\section{En la televisión}

En la serie de la década de 1960 Los Vengadores, se coloca un radio-rastreador en una pluma fuente para que el asesino pueda hallar a sus víctimas (Fountain Pen Network, 2015), pero es solo medio siglo después que la televisión nos muestra que la pluma es en sí misma el arma. En el episodio 16 de la octava temporada de CSI: Miami, una mujer es asesinada con una "pluma fuente de cuerpo de carbonato y punta de plata esterlina" que, para su desgracia, estaba muy a mano sobre el escritorio, por lo que los investigadores concluyen que se trata de un arma de oportunidad (Zuiker \& Donahue, 2010a, b, Figura 8).

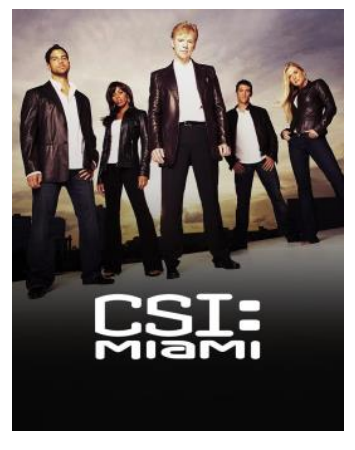

CSI: Miami, Columbia Broadcasting System

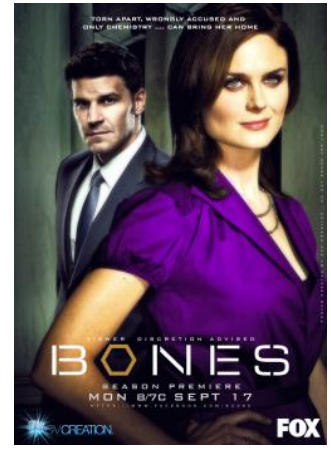

Bones, Fox Television

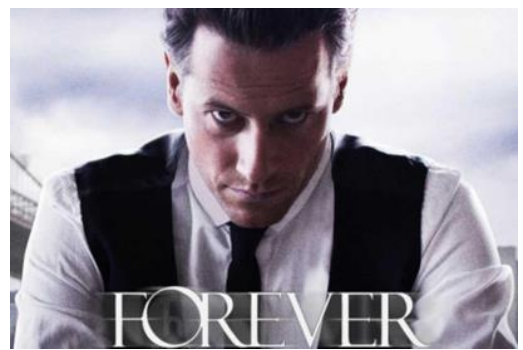

Forever, American Broadcasting Corporation

Figura 8. Series de televisión donde aparecen plumas fuentes como armas usadas en asesinatos. www.wikimedia.org

En el episodio "Socios en el Divorcio" de la serie Bones (2012), la víctima es un abogado, y cuando los forenses examinan el cuerpo, hallan en su garganta parte de las aguilillas de una pluma fuente, pista que acaba llevándolos hasta la asesina (Vissers, 2018). Si se hubiera tratado del Bic, mucho más difícil de rastrear, la historia habría sido diferente.

Más recientemente, en la serie Forever (2014-2015), hay un episodio en que la víctima es asesinada por ruptura de una arteria del cuello; el arma: una pluma fuente Lanier. Esta marca poco conocida existe en la vida real, y fabrica plumas fuente metálicas muy robustas que realmente podrían servir para fines agresivos (Fountain Pen Network, 2014a).

\section{En la vida real}

En la Segunda Guerra Mundial, el gobierno británico evaluó, y finalmente rechazó, la propuesta de dotar a sus agentes secretos con pluma fuentes que pudieran disparar balas reales (BBC, 1999, Figura 9). Se eligió la opción de dotar las plumas con dagas, más 
seguras, baratas y silenciosas. A inicios del 2017 se subastó una de ellas con una base de 500 libras (BBC, 2017) y seguramente yo habría pujado si me hubiera enterado a tiempo.

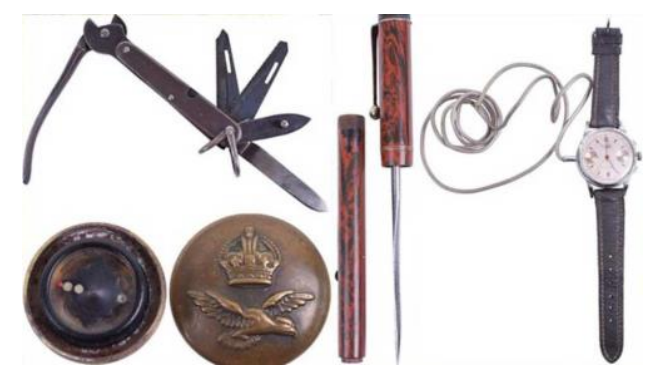

Figura 9. Armas de espía, incluyendo una pluma fuente de ebonita con una daga dentro (BBC, 1999).

Los británicos también fabricaron pluma fuentes explosivas, y posiblemente el agente Ian Fleming, quien luego se convirtió en escritor y creador de James Bond, conocía estas armas al igual que la propuesta de que pudieran disparar balas (Casciani, 2005).

Los estadounidenses también consideraron las pluma fuentes como armas. En 1952, la División de Operaciones Especiales en Fort Detrick, Maryland, desarrolló para la CIA dardos venenosos que se disparaban desde una pluma fuente y que posiblemente fueron usados en la Guerra de Vietnam (Otis \& Otis, 1988). No se ha hecho público, sin embargo, cómo eran y cómo funcionaban.

Pero es válido preguntarse, ya que hasta acá se trata de bombas o pistolas que parecen instrumentos de escritura, o de pluma fuentes con veneno en lugar de tinta, o de pura ficción: ¿es posible matar con una pluma fuente, bolígrafo o lápiz comunes y corrientes, en la vida real?

En efecto, los instrumentos de escritura pueden ser mortales si los usa alguien con conocimientos de anatomía humana. Esto se sabe por un estudio experimental hecho por el Dr. Roger Byard en la Universidad de Adelaida, Australia (Byard, Cains \& Gilbert, 2007, Figura 10). 
Figura 10. Estudio sobre instrumentos de escritura y otros objetos de uso diario usados como arma, American Journal of Forensic Medicine and Pathology.

Tristemente, justo el año que se publicó ese estudio, su validez se comprobó en la vida real cuando Jason Webster, estudiante de historia de la Universidad de Hull (Inglaterra) asesinó con un bolígrafo a la desdichada Rebecca Love, su exnovia que estudiaba biología marina en esa misma institución (Brooke, 2007).

Las pistolas que parecen pluma fuentes, pero disparan balas de verdad, fueron retomadas unos 70 años después de su formulación original en la Segunda Guerra Mundial, y lo sabemos porque en 2012, en Irkutsk, Siberia, un policía retirado asesinó a Andrei Melnikov con una pluma-pistola (Figura 11) que dos torneros rusos vendían por 100 dólares en el mercado negro (Parfitt, 2012). En este caso, la pistola no alerta a su víctima porque no parece un arma, al contrario de lo que le ocurrió a Tommy Lee, estudiante estadounidense fallecido cuando atacó a varios policías con un bolígrafo que confundieron con un cuchillo (Willmsen, 2017).

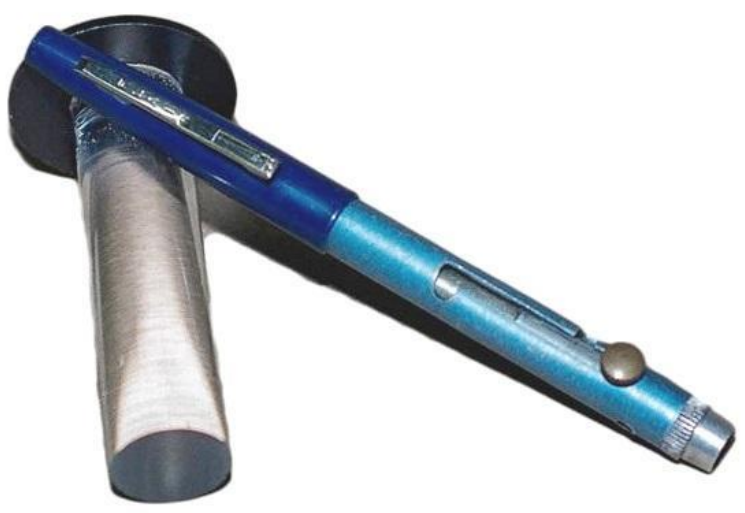

Figura 11. Bolígrafo-pistola, US Department of Justice, www.wikimedia.org

Cuando Kim Jong-nam, medio hermano del dictador norcoreano Kim Jong-un, fue asesinado en 2017, la prensa informó inicialmente que el arma había sido un bolígrafo con veneno (e.g. Lake, 2017), probablemente porque esta es un arma conocida de los espías norcoreanos, quienes tienen dos modelos, uno que inyecta directamente el veneno, y otro que dispara balas venenosas (Hancocks, \& Kwon, 2012). No fue así, pero en todo caso, el gobierno norcoreano le presta gran importancia a los instrumentos de escritura: la pluma asignada a Jong-un en su encuentro con el presidente estadounidense Donald Trump fue repetidamente frotada por un ayudante enguantado, y finalmente reemplazada por la hermana del dictador, justo antes de que él la tocara (Earle, 2018).

Decía mi profesor Luis Diego Gómez Pignataro que, estadísticamente hablando, casi cualquier condición humana se podía hallar en China, simplemente por la enorme cantidad de personas que viven allí, y fue precisamente en China donde, en abril del 2018, por primera vez en la historia, se usó una pluma fuente para secuestrar un avión. En el vuelo CA1350 de Air China, que viajaba de Changsha a Pekín, un hombre de apellido Xu colocó una pluma fuente contra la yugular de una persona de la tripulación, obligando a un 
aterrizaje de emergencia. El informe oficial, que como todo informe del gobierno chino debe tomarse cum grano salis, afirmó que el secuestrador había sido capturado y "pasado a evaluación psiquiátrica" (BBC, 2018).

Finalmente, para cerrar el ciclo, regreso a la antigua Roma. Según el historiador Suetonio, durante su famoso asesinato, el mismísimo Julio César (Figura 12) intentó defenderse con un instrumento de escritura: el estilete de la tablilla de cera con que tomaba notas rápidas durante las sesiones del senado (Strauss, 2015): si hubiera vivido 2000 años más tarde, seguramente se habría defendido con una pluma Montegrappa de plata y oro macizos.

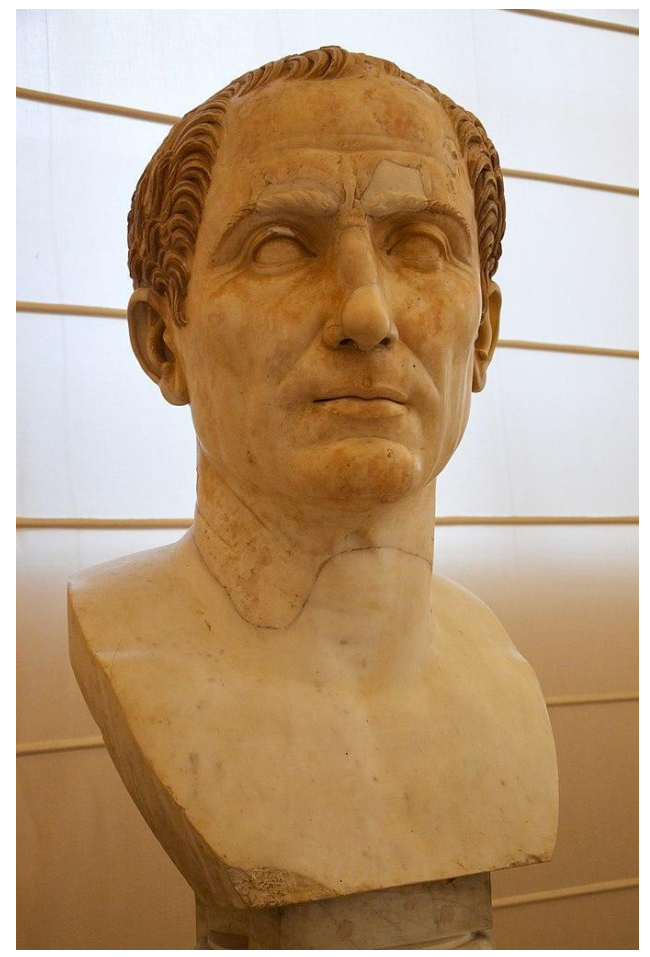

Figura 12. Julio César intentó defenderse de sus asesinos con el estilete que usaba para tomar notas rápidas en las reuniones. Busto del Museo Nápoles, fotografía por Carole Raddato, www.wikimedia.org

Agradezco a mi esposa Zaidett Barrientos Llosa, por sus recomendaciones para mejorar el manuscrito; a Carolina Seas por su ayuda con el formato y las figuras; y a Guillermo Coronado por alentarme a concluir este trabajo.

\section{Referencias}

BBC. (1999). Britain's secret WWII weapons revealed. Recuperado de http://news.bbc.co.uk/2/hi/uk_news/486391.stm

BBC. (2017, 11 de febrero). Vintage spy gadgets go under hammer. Recuperado de https://www.bbc.co.uk/news/uk-england-kent-38943163 
BBC. (2018). Air China plane 'pen' hostage drama suspect held by police. Recuperado de https://www.bbc.com/news/world-asia-china-43779810

Brooke, C. (2007). Jealous student murdered his lover by stabbing her with a pen. Recuperado de http://www.dailymail.co.uk/news/article-488167/Jealous-studentmurdered-lover-stabbing-pen.html

Byard, R. W., Cains, G. E., \& Gilbert, J. D. (2007). Use of a pig model to demonstrate vulnerability of major neck vessels to inflicted trauma from common household items. The American Journal of Forensic Medicine and Pathology, 28(1), 31-34.

Casciani, D. (2005). The real world behind James Bond. Recuperado de http://news.bbc.co.uk/2/hi/uk_news/magazine/4306221.stm

Daniher, R. J. (2007). Deadline. En Buchanan, D. (recopiladora). Deadly Ink 2007 Short Story Collection (p. 28-29). Nueva Jersey: Deadly Ink Press

Earle, G. (2018, 12 de junio). How to avoid a poisoned pen? Dailymail. Recuperado de https://www.dailymail.co.uk/news/article-5836919/Kim-Jong-uns-security-wiped-US-pen-signing-ceremony-sister-swapped-another.html

Fandom. (2018). Fatima Blush. Recuperado de http://jamesbond.wikia.com/wiki/Fatima_Blush

Fountain Pen Network. (2014a). Fountain Pens In Movies And Tv. Recuperado de http://www.fountainpennetwork.com/forum/topic/168373-fountain-pens-in-moviesand- tv/page-25

Fountain Pen Network. (2014b). Fountain Pen As Murder Weapon? Recuperado de http://www.fountainpennetwork.com/forum/topic/279485-fountain-pen-as-murderweapon/

Fountain Pen Network. (2015). Serie de la televisión británica, 1961-1969. Recuperado de http://www.fountainpennetwork.com/forum/topic/168373-fountain-pens-in-moviesand-tv/page-31.

Hancocks, P., \& Kwon, K. J. (2012, 26 de noviembre). Poison' pen mightier than sword for would-be North Korean assassin. CNN. Recuperado de https://edition.cnn.com/2012/11/25/world/asia/north-korea-assassinationweapons/index.html

Hill, K. (2013). Why The Joker's Magic Trick Wasn't So Serious. Scientific American Blogs. Recuperado de https://blogs.scientificamerican.com/but-not-simpler/why-thejoker-s-magic-trick-wasn-t-so-serious/

Krstović, J. (Editor). (1995). Roger Bacon - Introduction. Classical and Medieval Literature Criticism. Recuperado de www.enotes.com/topics/roger-bacon/criticalessays\#critical-essays-introduction 
Lake, E. (2017). As Kim Jong-un's half-brother is 'killed with pen poison' we look at how lethal substances were used in some of history's most sensational assassination attempts. The Sun, Londres. Recuperado de https://www.thesun.co.uk/news/2875485/as-kim-jong-uns-half-brother-is-killed-withpen-poison-we-look-at-how-lethal-substances-were-used-in-some-of-historys-mostsensational-assassination-attempts/

Levine, L. (2014). Killing Cupid. Nueva York: Kensington Books.

Lunetta P, Ohberg A, \& Sajantila A. (2002). Suicide by intracerebellar ballpoint pen. The American Journal of Forensic Medicine and Pathology, 23(4), 334-7.

McClory, K., \& Whittingham, J. (1983). Nunca digas nunca jamás. Recuperado de https://www.imdb.com/title/tt0086006/

McGregor, R. K., \& Lewis, E. (2000). Conundrums for the Long Week-end: England, Dorothy L. Sayers, and Lord Peter Wimsey. EE. UU: Kent State University Press.

O'Callaghan, L. (2017). Assassination John Wick style - 8 movie characters killed by pencils. Bath, Inglaterra: Games Radar. Recuperado de https://www.gamesradar.com/assassination-john-wick-style-8-movie-characterskilled-by-pencils/

Otis, J. L., \& Otis, T. (1988). Secrets of the CIA; documental. Recuperado de https://www.imdb.com/title/tt0475384

Parfitt, T. (2012, 16 de agosto). Russian pensioner kills neighbour with James Bond-style pen gun. The Telegraph, Londres. Recuperado de https://www.telegraph.co.uk/news/worldnews/europe/russia/9480119/Russianpensioner-kills-neighbour-with-James-Bond-style-pen-gun.html

Salvo, A.J. Di. 1989. Spanish Guides to Princes and the Political Theories in Don Quijote. Cervantes: Bulletin of the Cervantes Society of America 9.2: 43-60.

Strauss, B. (2015). The Death of Caesar: The Story of History's Most Famous Assassination. Nueva York: Simon \& Schuster

Vissers, K. G. F. (2018). Bones (TV Series).The Partners in the Divorce (2012) Plot. Recuperado de https://www.imdb.com/title/tt2301429/plotsummary

Willmsen, C. (2017, 23 de junio). Man killed by King County deputy was carrying a pen, not a knife as initially reported. The Seattle Times. Recuperado de https://www.seattletimes.com/seattle-news/crime/man-killed-by-king-county-deputywas-carrying-a-pen-not-a-knife-as-initially-reported/

Zuiker, A., \& Donahue, A. (2010a). CSI Miami Season 8 Episode 16. Recuperado de https://www.imdb.com/title/tt1586601 
Zuiker, A., \& Donahue, A. (2010b). CSI Miami Season 8 Episode 16 script. Recuperado de https://www.springfieldspringfield.co.uk/view_episode_scripts.php?tv-show=csimiami\&episode $=\mathrm{s} 08 \mathrm{e} 16$ 